\title{
THE TIME OF THE METROPOLIS: UNDERSTANDING URBAN AND SYSTEMIC DYNAMICS
}

\author{
Author(s) / Auteur(s) : \\ Paul VERMEYLEN \\ Urban planner, expert in EU territorial development \\ Architect(ISA), urbanist (ISURU), Public management (Solvay-ULB) \\ CityConsult Brussels \\ Paul.vermeylen@cityconsult.net
}

Abstract / Résumé :

How come that some EU cities are often presented as examples and monopolize the best positions in various rankings? They act not according to models, but according to a method which is mostly similar to Edgar Morin's concept of auto-eco-organization. Theirs actions are based on values: they are agile creative, supportive, sustainable. So how do they implement those guidelines?

Keywords / Mots-clés :

metropolization in EU Cities, method and values, agile,creative, solidair, sustainable, skills for systemic development

\section{The time of the metropolis. Understanding urban and systemic dynamics}

\section{The method}

Why do some European cities reach the podium of model cities ? Among them are Copenhagen, Barcelona or Bilbao, Nantes, Toulouse, Hamburg, Friburg, Amsterdam, Eindhoven, Rome or Turin. This presentation is based on multiple visits and meetings with the stakeholders in about forty cities for almost twenty years ${ }^{1}$ ). This long investigation shows that no model can be transposed or exported, as local situations always require tailored solutions.

The analysis is broadly based on the systemic approach, and in particular on Edgar Morin's works; through his concept of «self-eco-organisation », he insists on the method, as opposed to models. The method of self-organisation is based on values, some of which underpin the "metropolitan » method highlighted in this presentation.

On the one hand, the systemic analysis appears indeed to be the most appropriate method to monitor the dynamics, coincidences and needs of urban areas. For a few decades it has led many authors to analyse the polymorphous interactions on a territorial scale (2), whether between man and his environment or between the environment and the resources, and to take into account the flows between the outside and the inside, whose shapes have in fact become widely porous. On the other hand, ecosystems offer us the most useful paradigms to capture the urban dynamics and interact upon them; living resources are taken into account in order to promote both their conservation their sustainable use, in their multiple interactions with individuals.

The four values of metropolitan dynamics: agility, creativity...

The big European cities, long hindered by nation-states, have proved to be for a few decades the actual drivers of development. Their influence zones are expanding as they exercise power through the stocks they receive as much as through the flows that intertwine on their territories; these constantly growing flows entail interactions with increasingly distant territories. The best practices revealed by the investigation show that the cities have developed a unique expertise to articulate their actions with 
those of other entities (regions, medium-sized towns nearby or regions and towns that can be far away). Moreover, these agile metropolises establish cooperations of a multi-scale type (through articulation or interpenetration) across their systemic areas (e.g. the network of German urban areas, the urban area of Stuttgart, Øresund transnational area, the metropolitan community of Brussels under construction, etc.). Eventually, these agile cities maintain or renew their functional equilibrium (homeostasis) despite unstable constraints (e.g. Lille, Barcelona). In the end, the resilience capacities of the metropolitan system are thus boosted (Eindhoven, Vienna, Antwerp).

Economically speaking, the domestic product of the big European cities is generally at 140 to $180 \%$ of the European States, which demonstrate their strength. Moreover, these cities massively attract technological and non-technological innovation. But these model cities perceive the dead ends resulting from technological innovation alone (in terms of employment, of territorial anchoring deficit, etc.) ; they focus very much today on mobilising " creativity everywhere ».

Without giving up technological breakthroughs, they try to revitalise other potentials for prosperity, through cross-fertilisation and injection of creativity; these attempts often turn to the so-called strategies of the «blue ocean » (thanks to creativity, goods and services are not subject to competition due to their novelty). In view of a production where goods and services are more intertwined, these cities stimulate creativity at intersections of activities linked to residencial, social or public bases. Thus, the inhabitants'new requests and needs are more likely to be met. On the side of social capital, training and employment are closely articulated with these new bases for wealth, thus enhancing the expertise available (e.g. Copenhagen, Hamburg, Munich, Brussels), and not only «talents » $\left({ }^{3}\right)$.

In the end, creativity and social capital are on board to help « keep the metropolitan pot boiling ». This reflects the notion of " equifinality " : each of these creative metropolises initially moves on to its path thanks to its excellence and expertise panel (Munich, Toulouse, Grenoble). Then the panel is reinforced through agile cooperations (cf. supra; e.g. Kompetenznetze in Germany, cooperations between Nantes and Rennes, Guéret and Limoges, Hambourg and Øresund).

\section{...s olidarity, s us tainability}

The crisis is certainly hitting cities hard, and social urban crisis is noticeable every day. However, against the increasing powerlessness of the nets provided by welfare states and based on procedural solidarity (according to categories, requirements, etc.), some cities have taken over more than others. The investigation reveals that supportive cities are constantly inventing new ways of action, using the effects of proximity, to the point where they become de facto a « second pillar » of solidarity. They are active in redefining their territorial boundaries, the stake being to organize solidarity, particularly on tax (e.g. Eindhoven, Stockholm), or in reshaping their actual labour pool (Vienna, Amsterdam, Bordeaux). While considering at first the multiple causes of exclusion, they focus on (re)vitalising the "warm solidarities», through policies aiming at social and civic cohesion (Brussels, Hamburg, Birmingham). They tear down the walls surrounding inner cities or new neglected territories, sometimes located on the fringe of their area (Rome, Turin, Dublin, Lille).

For that purpose, supportive cities activate new «societal combinations » between stakeholders, including to better promote their social capital or integrate their social outcasts (Hamburg, Turin, Sofia). These new alliances aim in particular at «re-monetising» tasks of societal interest linked to emerging requests and needs, for example population ageing (Eindhoven, Birmingham, GuéretLimoges).

Cities have become major players in sustainable development because of the functions they fulfill (mobility, waste management, etc.). Model cities mobilise a large number of ecosystemic pools : generating new relations with nature, including economically upgrading their fringes through farming organised in short cycle; recycling buildings and integrating their time dimension (conversion of buildings, restoration) ; opening to the new prospects of circular economy, of energy or waste to make consumers come together (e.g. Lille, Rouen, Besançon, Antwerp, Aachen, Vienna, Güssing, Friburg). In many cases these consumers have paradoxically partly become energy, goods or service producers. Seeking for new balances -homeostasia as a dynamic balance that maintain or regenerate life- is 
always present, and the paradigm of the « circular » economy illustrates the new relationships between man and nature.

\section{Tools of syste mic action applied to the city}

In order to comply with those values, the modes of action are changing. This brief presentation illustrates the driving force of verbs. Taking advantage of malleability to open to new interdisciplinary fields. Irrigating the seeds of creativity, in the proliferating way of the rhizome, to expand new interactive fields. Merging practices to create new modes of action. Ensuring porosity between fields of action, between borders, whether institutional, physical or mental. Consolidating and encouraging restoration rather than being fascinated by « large-scale projects » designed by the brains of some lone " geniuses». These modes of "lateral thinking » make it possible to look beyond "silos ", to juggle with factors influencing the evolution of systems.

\section{REFERENCES}

(1) Paul Vermeylen 2014. Le temps de la métropole. Agile, créative, solidaire, durable. Parcours en Europe. Ed. L'Harmattan.

(2) See e.g. Jane Jacobs 1992. Les villes et la richesse des nations. Ed Boréal. Or Denise Pumain, Thérèse Saint-Julien, Léna Sanders. 1990. Villes et auto-organisation. Préface d'Ilya Prigogine.

(3) Richard Florida 2002. The Rise of the Creative Class. Basic Books. 